Copyright @ 2015 by Academic Publishing House Researcher

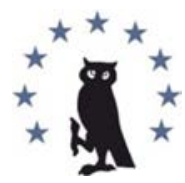

Published in the Russian Federation

European Researcher

Has been issued since 2010 .

ISSN 2219-8229

E-ISSN 2224-0136

Vol. 94, Is. 5, pp. 389-402, 2015

DOI: $10.13187 /$ er.2015.94.389

www.erjournal.ru

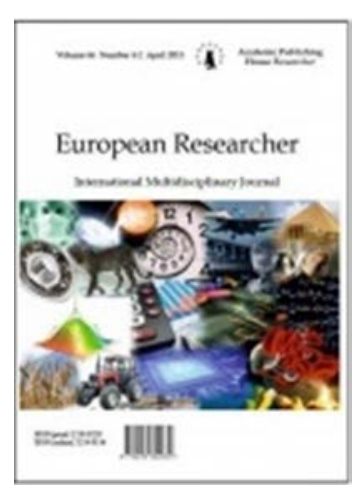

UDC 37

\title{
Modeling Training of Future Teachers Aimed on Innovation Activities Based on the System of Design Features
}

Yury S. Tyunnikov

Sochi state university, Russian Federation

26 a, Sovetskaya Str., Sochi 354000

Doctor of Pedagogic Sciences, Professor

\begin{abstract}
Modeling of training system of future teachers aimed on innovation activities performed in a certain project logic and procedures, which is possible only through a specific set of design features, based on capability and peculiar properties of the university. The article is formulated and solved the problem of design features, revealing in its set the characteristic properties, organization and functioning of training system aimed on innovation in specific terms of professional education.

Keywords: training system of future teachers aimed on innovation activities, modeling of pedagogical system, design features of modeled system.

\section{Введение}

Построение системы подготовки будущих педагогов к инновационной деятельности, ориентированной на возможности и особенности вуза, имеет свою определенную логику и форму описания. Форма описания имеет вид проектных характеристик, которые раскрывают особенности и возможности практической реализации системы подготовки к инновационной деятельности в заданных условиях вузовского обучения в проекции на все звенья профессионального образования.

Следует признать, что в настоящее время вузовская практика подготовки педагогов к инновационной деятельности сталкивается с немалыми трудностями, которые невозможно преодолеть, ориентируясь только на рекомендации по отдельным аспектам подготовки или же общие требования ее организации. Понятно, что моделируемая система подготовки должна рассматриваться не в одном, отдельно взятом аспекте, а в их инвариантном наборе как целостность. Последнее же становится возможным только при наличии определенного набора проектных характеристик.

Ранее выполненные исследования (В.А. Адольф [1], К. Ангеловски [2], Н.Ф. Ильина [1], В.С. Лазарев [3], Б.П. Мартиросян [3; 4], П.И. Пидкасистый [5], Л.С. Подымова [6], В.А. Сластенин [6], Е.Ю. Ривкин [7] и др.) позволяют не только сделать вывод о имеющимся разрыве между общим и единичным, системой и ее аспектом, но и сформировать необходимую основу для его преодоления. Они позволяют выстроить логику и процедуры моделирования системы подготовки к инновационной деятельности применительно к заданным условиям функционирования, выполнить разработку системы адекватных
\end{abstract}


проектных характеристик в соотнесении с проектными процедурами в рамках общей стратегии моделирования.

\section{Методы и материалы}

Описание системы подготовки к инновационной деятельности как объекта педагогического проектирования производится в рамках отношений «система профессиональной подготовки будущего педагога - система подготовки будущего педагога к инновационной деятельности», «система подготовки к инновационной деятельности структурные составляющие системы подготовки к инновационной деятельности». Вычленение проектных характеристик моделируемой системы подготовки будущих педагогов к инновационной деятельности осуществляется в методологии системного подхода методами компонентного и структурно-функционального анализа.

\section{Обсуждение}

Анализ существующих подходов и разработок показывает, что построение системы подготовки к инновационной деятельности, приближенной к реальной практике профессионального образования, следует осуществлять в дедуктивной логике с поэтапным выполнением следующих проектных процедур:

спецификация подготовки будущих педагогов к инновационной деятельности;

генерализация подготовки к инновационной деятельности;

построение содержания подготовки к инновационной деятельности;

логико-смысловое структурирование подготовки к инновационной деятельности;

дифференциация и интеграция междисциплинарного ресурса;

технологизация подготовки к инновационной деятельности;

формирование организационно-управленческой поддержки.

C учетом обозначенных проектных процедур и общих дескрипторов педагогической системы как таковой можно представить подготовку к инновационной деятельности как объект моделирования в следующих группах проектных характеристик: субъектнопредметной, целе-функциональной, контент-ресурсной, структурно-логической, структурноинтегративной, инструментально-технологической, организационно-управленческой. Проектные характеристики в представленном наборе дают необходимые представления о субъекте обучения, ценностно-смысловых ориентирах, составе и структуре учебного содержания, логике развертывания содержания (в целом и отдельных частях), формах, методах и технологиях обучения, организационно-педагогических условиях.

Покажем логику основных шагов и процедур разработки модели подготовки будущих педагогов к инновационной деятельности с опорой на систему проектных характеристик.

\section{Спецификация подготовки к инновационной деятельности}

Спецификация направлена на получение исходной информации о субъекте и предмете подготовки к инновационной деятельности.

Субъект подготовки к инновационной деятельности - это обучаемый, которого характеризуют профиль профессиональной подготовки, выполняемые инновационные функции, социальные и профессиональные роли, ранее сформированные элементы инновационной деятельности, связанные с решением определенных задач.

Предмет подготовки к инновационной деятельности - это профессиональные (основные и вспомогательные) компетенции, которые подлежат формированию, развитию и коррекции в процессе обучения. В предмет, соответственно, входят характерные для основных и вспомогательных компетенций наборы знаний, умений и навыков; определенные классы адаптационных, ролевых, мотивационных и иных реакций субъекта, подлежащих формированию и коррекции.

Состав и содержание субъектно-предметных характеристик уточняются с позиций компетентностного подхода [8; 9] в рамках тех задач, которые непосредственно будут выполняться педагогом в ближайшей перспективе. К субъектно-предметным характеристикам моделируемой системы следует отнести: профиль профессиональной подготовки будущего педагога; практические задачи инновационной деятельности; основные виды инновационной деятельности; типовые ситуации инновационной 
деятельности; роли субъектов инновационной деятельности; профессионально-личностные барьеры.

Профиль профессиональной подготовки будущего педагога. Проектная характеристика показывает, с каким педагогом мы имеем дело, какова область его профессиональной деятельности, какое место он занимает в общем образовательном процессе, какие функции выполняет.

Практические задачи инновационной деятельности. Данная характеристика отражает состав задач, с которыми педагог сталкивается в своей практической деятельности. При формировании информационной базы проводимой подготовки практические задачи инновационной деятельности играют важную роль. Они позволяет дать в рамках заданной стратегии обобщающее, сбалансированное отображение основных этапов и процедур инновационной деятельности. Например, этапы и процедуры инновационной деятельности в части обеспечения системной поддержки внедрение ФГОС нового поколения и др.

Основные виды инновационной деятельности. Проектная характеристика показывает, по каким видам инновационной деятельности предполагается осуществлять подготовку. К таким видам деятельности относятся аналитическая, экспертная, прогностическая, консультационная, проектная, организационно-управленческая и др.

Типовые ситуации инновационной деятельности. Понимание и решение практических задач инновационной деятельности происходит в определенных смысловых структурах, которые отражают семантику поставленной задачи и ее связь с внешними условиями и обстоятельствами, иначе говоря, с некоторой ситуацией. Типовые ситуации инновационной деятельности представляют определенный интерес для организации рассматриваемой подготовки, поскольку на их основе формируется необходимой набор дидактических ситуаций.

Роли субъектов инновационной деятельности. В инновационном педагогическом процессе ее участниками выполняются различные роли (инициатора, генератора идей, эксперта, проектировщика, методиста и др.), которые следует отобрать и представить для последующего функционально-ролевого распределения в системе профессиональной подготовки педагога.

Профессионально-личностные барьеры. Характеристика отражает имеющиеся несоответствия между нормативным и фактическим уровнем готовности к инновационной деятельности, указывает на предполагаемый результат проводимой подготовки. Данная характеристика очерчивает круг барьеров инновационной деятельности и барьеров саморегуляции профессионально-личностного развития, реально влияющих на уровень готовности будущих педагогов к инновационной деятельности [10].

Субъектно-предметные характеристики имеют разноплановое назначение. Они позволяют определиться в специфике профессиональной деятельности будущего педагога, конкретизировать целевую направленность подготовки к инновационной деятельности, получить необходимый исходный материал для разработки учебного содержания, решения ряда вопросов, связанных с установлением взаимосвязи дисциплинарного обучения, педагогических практик и научно-исследовательской работой студентов, построения образовательных технологий, организации процесса саморегуляции профессионально-личностного развития.

Здесь уместно отметить один достаточно существенный момент. Традиционно разработка содержания подготовки к инновационной деятельности осуществляется по схеме «готовность к инновационной деятельности - специальные знания, умения, навыки». Путем декомпозиции основных и вспомогательных компетенций, определяющих готовность к инновационной деятельности, разработчики стремятся получить некоторый «сухой остаток» в виде нормативного набора умений и навыков и сопутствующих им знаний, которые затем включаются в содержание соответствующих образовательных программ или образовательных моделей. При таком подходе в значительной степени иллюминируются практические задачи, которые возникают непосредственно в процессе модернизации образования. Фактически они сводятся к отдельным функциям или подфункциям инновационной деятельности. Что же касается ситуаций инновационной деятельности, в рамках которых происходит решение практических задач, то они при такой схеме практически полностью игнорируются. Тем самым нарушается целе-функциональная 
структура знаний, умений и навыков. Другими словами, теряется из виду то, ради чего они должны формироваться, по поводу чего, собственно, и должен строиться сам процесс подготовки к инновационной деятельности.

Принципиально иной подход к построению учебного содержания реализуется, если придерживаться схемы «готовность к инновационной деятельности - эквиваленты готовности - группы специальных знаний, умений, навыков».

Прежде всего, дадим пояснения относительно того, что следует понимать под эквивалентами готовности к инновационной деятельности. Эквивалентами является то, что прямо и непосредственно не относится к структуре и дискретным частям профессиональной готовности, другими словами, к способностям и мотивационно-потребностной сфере педагога, но, вместе с тем, определенным образом может характеризовать их наличие и состояние. Речь идет о функциях, ролях, видах инновационной деятельности, типовых практических задачах, ситуациях инновационной деятельности разного типа и вида, барьерах инновационной деятельности и барьерах профессионально-личностной саморегуляции. Все они имеют важное значение для анализа готовности педагога того или иного профиля к инновационной деятельности и формирования информационной базы построения междисциплинарной программы (см. подробнее [11]).

Формирование исходной информационной базы подготовки к инновационной деятельности (в наборе соответствующих субъектно-предметных характеристик) начинается c определения особенностей профессиональной деятельности педагога и анализа практических задач инновационной деятельности. С учетом профиля подготовки педагога и состава типовых задач определяются основные виды инновационной деятельности, типовые ситуации, функции и роли субъектов инновационной деятельности, профессиональноличностные барьеры. Тем самым работа по формированию информационной базы системы подготовки к инновационной деятельности завершается. Именно такой подход, на наш взгляд, позволяет выявить в требуемой полноте особенности профессиональной готовности будущего педагога к инновационной деятельности и то исходное содержание, которое необходимо для построения междисциплинарной модульной образовательной программы.

\section{Генерализация подготовки к инновационной деятельности}

Генерализация подготовки к инновационной деятельности означает выделение главных целевых ориентиров моделируемой системы. Она включает процедуры целеполагания и целепостановки, что находит свое отражение в целе-функциональных характеристик моделируемой системы. Речь идет о генерализации готовности к инновационной деятельности как интегрального качества личности педагога и как ценностно-смыслового приоритета его квалификации, декомпозиции интегрального качества на структурные составляющие и отдельные элементы в виде дерева педагогических целей.

В группе целе-функциональных характеристик представлены: социокультурные функции инновационной деятельности педагога; ценностно-смысловые установки, определяющие целевую направленность и педагогические цели подготовки будущих педагогов к инновационной деятельности; консолидирующий замысел рассматриваемой подготовки.

Социокультурные функции. Характеристика устанавливает сопряженность системы подготовки к инновационной деятельности с другими процессами и системами профессиональной подготовки будущих педагогов. Система подготовки к инновационной деятельности, кроме прямого целевого назначения, выполняет более широкие функции, связанные с общим развитием будущего педагога, его адаптацией в сфере образования, многоплановой социокультурной ориентировкой.

Целевая направленность. Характеристика дает представление о готовности к инновационной деятельности как главном ориентире моделируемой системы и координации взаимодействия ее отдельных звеньев. Применительно к конкретному образовательному процессу готовность к инновационной деятельности рассматривается на уровне заданной совокупности профессиональных компетенций и на уровне отдельной профессиональной компетенции. В первом случае она предстает как интегральная целостность, во втором - как фрагмент этой целостности, его структурная составляющая. 
Система педагогических целей. Данная характеристика показывает, в какой системе педагогических целей конкретизируется целевая направленность подготовки к инновационной деятельности.

Целепостановка, направленная на создание достоверной, практически реализуемой система целей, проводится в два этапа. На первом этапе профессиональная готовность к инновационной деятельности подвергается декомпозиции, в ходе которой ее структурные составляющие переводятся в иерархическую систему педагогических целей. На втором цели группируются в привязке к составу междисциплинарных модулей, тем самым устанавливается последовательность реализации модулей в логике рационального управления учебно-познавательной деятельности.

Нам представляется не противоречивой в указанном смысле трехуровневая иерархия (дерево) целей:

готовность будущих педагогов к инновационной деятельность (первый уровень);

основные и вспомогательные компетенции инновационной деятельности как структурные составляющие готовности (второй уровень);

специальные группы знаний, умений, навыков, образующие основные и вспомогательные компетенции (третий уровень).

Разработка системы педагогических целей (прежде всего, второго и третьего уровня) осуществляется на конкретном материале, полученном в ходе формирования информационной базы системы подготовки к инновационной деятельности.

Консолидирующий замысел. Согласование ценностно-смысловых ориентиров в стратегии и логике подготовки к инновационной деятельности осуществляется посредством конфигурирования указанных подсистем целей. Функцию главного регулятора в процедуре конфигурирования педагогических целей выполняет консолидирующий замысел проводимой подготовки.

Проблема замысла в практике педагогического моделирования обычно не обсуждается. Предполагается, что если педагогические цели заданы, то есть известно, какие именно качества личности, знания и технологические операции следует формировать у той или иной категории обучаемых, то тем самым замысел образовательного процесса тоже определен. Наша точка зрения в этом вопросе иная. Замысел образовательного процесса это нечто большее, чем педагогические цели. Если цели определяются по существу системой знаний, умений и навыков, которые соответствуют определенному составу компетенций, то, говоря о замысле, нужно, кроме того, учитывать, иные характеристики планируемого образовательного процесса.

Консолидирующий замысел определяет стратегию и логику развертывания системы подготовки к инновационной деятельности. В свою очередь существенное влияние на выбор того или иного замысла оказывают контент-ресурсные характеристики моделируемой системы, которые обеспечивают содержательное наполнение образовательного процесса в заданной стратегии и логике. Консолидирующий замысел также непосредственно связан с логико-структурными характеристиками моделируемой системы, в частности, с логикосемантической компоновкой образовательного процесса в масштабе реального времени.

Принципиальные отличия, к примеру, имеют педагогическая система, построенная в замысле подготовки будущих педагогов к внедрению ФГОС нового поколения, и педагогическая система, построенная в замысле подготовки студентов к решению практических задач обогащения предметного обучения новыми методическими элементами. Логико-семантическая развертка этих систем имеют существенное отличие. Они построены в разной функциональной специфике и на разных принципах. Это немаловажное обстоятельство нужно учитывать. Кроме того, можно обнаружить, что при моделировании этих систем приходится оперировать разным содержанием и разными технологиями обучения. Отличие также обнаруживаются в междисциплинарной интеграции, способах и формах организации образовательного процесса.

\section{Построение содержания подготовки к инновационной деятельности}

Формирование содержания подготовки будущих педагогов к инновационной деятельности в рамках междисциплинарной модульной программы ориентировано на разработку состава и содержания междисциплинарных модулей. Разделение 
образовательного процесса на автономные модули функционально необходимо. Содержательная завершенность и независимость модулей друг от друга придают моделируемой системе необходимую гибкость.

В содержании каждого модуля, наряду с традиционными учебными элементами знаниями, умениями, навыками, - выделяются дидактические ситуации инновационной активности, барьеры инновационной деятельности, барьеры саморегуляции готовности к инновационной деятельности. Последние рассматриваются в нормативном значении, поскольку они позволяют более точно настроить содержание отдельных модулей и программы в целом на решение поставленных задач. В этой связи представляется необходимым обозначить в конкретных проектных характеристиках, какие именно ситуации и барьеры предполагается реализовать в том или ином междисциплинарном модуле (о барьеросодержащих структурах учебного содержания см. [6; 7]).

В группу основные контент-ресурсных характеристик включены: состав междисциплинарных модулей; состав дидактических ситуаций; состав барьеров инновационной деятельности и барьеров профессионально-личностной саморегуляции; информационные и операционно-деятельностные элементы содержания.

Состав междисциплинарных модулей. Проектная характеристика указывает, какой набор междисциплинарных модулей в набольшей степени отвечает поставленным целям и позволяет формировать у студентов основные и вспомогательные компетенции инновационной деятельности, профессиональные качества педагога, мотивацию инновационной активности, мировоззренческие идеи и установки и т.п.

Состав дидактических ситуаций. Проектная характеристика показывает, с помощью каких ситуаций и какой степени сложности в образовательном процессе актуализируются структуры учебно-познавательной деятельности обучаемых. Дидактические ситуации имеют четко выраженный проблемный характер. Они конкретизируют содержание образовательного процесса в специфических структурах учебно-познавательной деятельности. Анализ таких ситуаций в различном сочетании составляет большую часть междисциплинарного практикума инновационной деятельности и саморегуляции готовности к ней.

Состав барьеров инновационной деятельности и барьеров профессиональноличностной саморегуляции. Основные образовательные результаты (восприятие и проработка новой информации, решение проблем и практических задач инновационной деятельности, концептуализация позиций инновационной активности и др.) достигаются в процессе преодоления характерных барьеров. Как элементарная структура учебного содержания барьер представляет собой дидактический аналог барьера инновационной деятельности или барьера профессионально-личностной саморегуляции. За каждым барьером стоят свои вполне конкретные наборы учебных элементов в виде знаний тех или иных сторон инновационной деятельности и связанных с ней объектов (предметов, процессов, явлений), а также способов реализации данных знаний. Проектная характеристика показывает, какой набор барьеров необходимо использовать в процессе формирования у студентов готовности к инновационной деятельности.

Информационные элементы содержания. Информационными элементами содержания могут быть представления (о различных сторонах образования, ситуациях педагогической деятельности и т.п.), понятия (о различных педагогических явлениях, принципах и закономерностях функционирования педагогических систем, целях, задачах, методах и технологиях инновационной деятельности и т.п.), мировоззренческие идеи, концептуальные обобщения и др. Проектная характеристика показывает, какие информационные элементы центрируются вокруг барьеров инновационной деятельности и барьеров саморегуляции готовности к инновационной деятельности и определяют содержание дидактических ситуаций.

Операционно-деятельностные элементы содержания. Проектная характеристика показывает, какие именно операционно-деятельностные элементы определяют содержание дидактических ситуаций. Операционно-деятельностные элементы различного характера и содержания (практико-технологические, экономические, логистические, организационные, коммуникативные и др.) распределяются между всеми образовательными модулями, однако 
в концентрированном и наиболее систематизированном виде они представлены в содержании междисциплинарного практикума.

Дифференциацию и содержательную спецификацию междисциплинарных модулей следует проводить по двум основаниям - практические задачи инновационной деятельности и практические задачи саморегуляции готовности к инновационной деятельности. В этом случае выделенный состав междисциплинарных модулей будет соответствовать общей структуре программы подготовки к инновационной деятельности, включающей разделы «Инновационный педагогический процесс», «Инновационная деятельность педагога», «Саморегуляция готовности к инновационной деятельности», «Практикум инновационной деятельности и саморегуляции готовности к ней». В этой связи можно рекомендовать следующий состав междисциплинарных модулей:

(1) модуль «Инновационный педагогический процесс». Модуль содержит общие сведения об инновационном процессе, его структуре, функциях, особенностях реализации в сфере образования;

(2) модуль «Культурологический анализ образования». Модуль содержит общие сведения о культурологическом анализе сферы образования: назначении, общей методологии и методах выполнения;

(3) модуль «Поиск педагогической новации». Модуль включает информацию о методологии поиска и экспертизы педагогического новшества;

(4) модуль «Проектное и методическое сопровождение педагогической новации». Модуль ориентирован на демонстрацию методологии и методов решения практических задач инновационной деятельности, связанных с проектными разработками и созданием учебно-методического материала для внедрения педагогической новации.

(5) модуль «Управление инновационным педагогическим процессом». Модуль раскрывает управленческую модель и особенности организационных условий осуществления инновационного процесса, связанного с освоением того или иного педагогического новшества;

(6) модуль «Деловые коммуникации в инновационном педагогическом процессе». Модуль предназначен для систематизации знаний студентов по основным вопросам деловой коммуникации при коллективном решении практических задач инновационной деятельности, включая технологии коллективных дискуссий и принятия совместных решений;

(7) модуль «Саморегуляция готовности к инновационной деятельности». Модуль содержит необходимую информацию о функциях, механизмах, способах и приемах профессионально-личностной саморегуляции педагога в условиях перманентной модернизации образовательного процесса;

(8) модуль «Практикум инновационной деятельности и саморегуляции готовности $\kappa$ ней». Данный модуль является практическим приложением всех вышеназванных модулей и служит для отработки в реальных или имитируемых условиях основных методов и приемов инновационной деятельности, а также методов и приемов саморегуляции готовности к инновационной деятельности.

Понятийно-терминологическое наполнение модуля «Инновационный педагогический процесс» осуществляется на базе тезауруса инновационного педагогического процесса.

Содержание модулей «Культурологический анализ образования», «Поиск педагогической новации», «Проектное и методическое сопровождение педагогической новации», «Управление инновационным педагогическим процессом» и «Деловые коммуникации в инновационном педагогическом процессе» формируется на основе тезауруса инновационной деятельности педагога.

Содержание модуля «Саморегуляция готовности к инновационной деятельности» производится $\mathrm{c}$ опорой на тезаурус саморегуляции готовности к инновационной деятельности.

Содержание модуля «Практикум инновационной деятельности и саморегуляции готовности к ней» представляет собой определенную систему дидактических заданий и ситуаций по отработке на практике процедур и приемов инновационной деятельности, а также процедур и приемов саморегуляции формируемой готовности. Такая система разрабатывается с учетом избранной стратегии освоения того или иного педагогического 
новшества и соответствующей номенклатуры практических задач инновационной деятельности.

\section{Логико-смысловое структурирование подготовки к инновационной деятельности}

Логико-смысловое структурирование определяет логику развертывания процесса подготовки к инновационной деятельности в целом и логику развертывания его частей в рамках отдельных междисциплинарных модулей. Основные структурно-логические характеристики дают необходимые представления о статусе отдельных этапов подготовки к инновационной деятельности, распределении междисциплинарных модулей в логике проводимой подготовки, распределении ролевых функций субъектов образовательного процесса, временном регламенте отдельных этапов и подготовки в целом.

Этапы подготовки к инновационной деятельности. Наличие четко дифференцированных этапов подготовки к инновационной деятельности, их взаимосвязь и преемственность являются важным условием управляемости моделируемой системы. Разбивка подготовки на этапы исходит в данном случае из идеи последовательного изменения качественного состояния профессиональной готовности будущего педагога в процессе профессионального образования. Проектная характеристика фиксирует основные этапы подготовки студентов к инновационной деятельности с учетом целе-функциональных и контент-ресурсных характеристик моделируемой системы, а также бюджета учебного времени, отводимого на реализацию того или иного этапа в масштабе всего профессионального образования педагогов.

Опираясь на ресурсные возможности образовательных программ высшего педагогического образования и учитывая рекомендации В.А. Адольфа [1], ВайндорфСысоева [12], С.Г. Григорьевой [13], Н.Ф. Ильиной [1], Л.С. Подымовой [6], В.А. Сластенина [6], 3. Абасов [14], В.Н. Фокина [15] и др., можно предложить следующую дифференциацию этапов подготовки будущих педагогов к инновационной деятельности: пропедевтический этап, структурно-формирующий этап, практико-регулятивный этап.

Пропедевтический этап направлен на ознакомление студентов с социокультурными функциями и практическими задачами инновационной деятельности в сфере образования, структурой, этапами, основными принципами и процедурами инновационного педагогического процесса, задачами и принципами саморегуляции готовности к инновационной деятельности. Этап реализуется в первом семестре на материале общих гуманитарных и социально-экономических и общепрофессиональных дисциплин: «Иностранный язык», «Отечественная история», «Основы самостоятельной работы студентов», «Математика и информатика», «Педагогическая антропология», «Педагогика», «Психолого-педагогический практикум».

Структурно-формирующий этап направлен на формирование информационных, операционно-деятельностных и мотивационно-волевых компонентов готовности к инновационной деятельности, опыта саморегуляции профессионально-личностного развития будущих педагогов в контексте практических задач модернизации образовательного процесса. Особый акцент делается на овладении методологией и технологией инновационной деятельности, способами и приемами саморегуляции профессионально-личностного развития. Этап реализуется во втором-четвертом семестрах на материале всех изучаемых дисциплин гуманитарного и социально-экономического, математического и естественно-научного и профессионального блоков, в ходе написания курсовых работ, прохождения учебной практики и выполнения различных видов самостоятельных и исследовательских работ студентов.

Практико-регулятивный этап направлен на развитие у будущих педагогов опыта инновационной деятельности в конкретных условиях образовательных учреждений как базовых площадок педагогических практик, опыта саморегуляции готовности к инновационной деятельности, включая отработку процедур ее самодиагностики, самокоррекции и саморазвития. Этап реализуется с пятого семестра и до окончания вуза на материале дисциплин профессионального и специального блоков, а также в ходе прохождения педагогических практик, выполнения выпускной квалификационной работы и участия в научно-исследовательской работе выпускающих кафедр. 
Взаимосвязь междисциплинарных модулей. Проектная характеристика показывает, какие междисциплинарные модули обеспечивает подготовку студентов к инновационной деятельности на том или ином этапе. Несмотря на функциональные и содержательные отличия, модули имеют между собой устойчивые связи и по существу объединены единой логикой. Данное обстоятельство имеет существенное значение для практического воплощения консолидирующего замысла моделируемой системы и согласования модулей с этапами подготовки к инновационной деятельности.

На первом, пропедевтическом этапе подготовки реализуется модуль «Инновационный педагогический процесс».

На втором, структурно-формирующем этапе реализуются в приведенной последовательности следующие модули: «Культурологический анализ образования», «Поиск педагогической новации», «Проектное и методическое сопровождение педагогической новации», «Управление инновационным педагогическим процессом». Данная последовательность синхронизирована с применением модуля «Деловые коммуникации в инновационном педагогическом процессе» и модуля «Саморегуляция готовности к инновационной деятельности».

На третьем, практико-регулятивном этапе реализуется междисциплинарный модуль «Практикум инновационной деятельности и саморегуляции готовности к ней».

Функционально-ролевые распределения. Характеристика указывает на состав ролевых функций субъектов инновационной деятельности, воспроизводимых в образовательном процессе, их распределение по отдельным этапам подготовки к инновационной деятельности, динамику диспозиций (познавательных, практико-технологических, коммуникативных, поведенческих), генерируемых в ситуациях обсуждения и разрешения проблем модернизации образования. Следует подчеркнуть, что инновирование в сфере образования имеет преимущественно коллективный характер [16; 17]. Для ее успешного осуществления необходимы умения делового общения и коллективного творческого обсуждения возникающих проблем: умения налаживать диалог, дискутировать по спорным вопросам, вычленять в ходе обсуждения нужную информацию, аргументировано излагать собственную позицию, правильно оценивать позицию оппонентов и др.

\section{Дифференциация и интеграция междисциплинарного ресурса}

Дифференциация междисциплинарного ресурса подготовки к инновационной деятельности направлена на закрепление модулей за конкретными дисциплинами, педагогическими практиками и научно-исследовательской работой студентов. Напомним в этой связи, что все модули программы по своему содержанию являются междисциплинарными. Это означает, что каждый отдельно взятый модуль реализуется на материале разных дисциплин, а также на материале педагогических практик и научноисследовательской деятельности.

Интеграция междисциплинарного ресурса предполагает определение приоритетов междисциплинарной интеграции и семантических структур, которые конституируют процесс подготовки к инновационной деятельности, придавая ему внутреннюю целостность и необходимую целевую направленность.

В группу структурно-интегративных характеристик моделируемой системы включены следующие проектные характеристики: локальная привязка междисциплинарных модулей, приоритеты междисциплинарной интеграции, логико-содержательные основания междисциплинарной интеграции, масштаб междисциплинарной интеграции, уровень междисциплинарной интеграции.

Локальная привязка междисциплинарных модулей. Локальная привязка позволяет позиционировать модули относительно тех дисциплин, на базе которых они реализуются. Так, модуль «Проектное и методическое сопровождение педагогической новации» функционально и содержательно привязан к психолого-педагогическим дисциплинам, а модуль «Практикум инновационной деятельности и саморегуляции готовности к ней» в значительной мере привязан к программам педагогических практик, различным видам самостоятельной работы и научно-исследовательской работе студентов. Содержание модулей «Деловые коммуникации в инновационном педагогическом процессе» и «Саморегуляция готовности к инновационной деятельности» распределяется между 
дисциплинами разных циклов, но в тоже время в систематизированном виде может быть представлено в специально разработанных дисциплинах по выбору.

Приоритеть междисциплинарной интеграции. Система подготовки к инновационной деятельности построена на образовательном ресурсе междисциплинарной интеграции. Образовательные приоритеты интеграции сосредоточены на ключевых структурах формирования инновационной активности и предполагают высокую степень консолидации усилий преподавателей дисциплин разных циклов, руководителей и методистов педагогических практик, организаторов и руководителей научноисследовательской деятельности студентов. Следуя нашему концептуальному подходу, мы полагаем, что интеграция, обеспечивающая оптимальное развертывание подготовки к инновационной деятельности, должна соответствовать четырем приоритетам: инновационный педагогический процесс, методология и технология инновационной деятельности, опыт индивидуальной и групповой инновационной деятельности, саморегуляция готовности к инновационной деятельности.

Логико-содержательные основания междисциллинарной интеграции. Междисциплинарная интеграция должна отвечать объективной специфике и требованиям целостности подготовки к инновационной деятельности $[18 ; 19]$. Принципиальное значение для интеграции имеют логико-содержательные основания, которые, с одной стороны, указывает, в какой последовательности разворачивается междисциплинарная интеграция в рамках того или иного образовательного приоритета, а с другой, - на те содержательные опоры, которые регулируют взаимосвязь учебных дисциплин, педагогических практик и научно-исследовательской деятельности студентов.

В качестве логико-содержательного основания интеграции по приоритетному направлению «Инновационный педагогический процесс» выступает понятийнотерминологический тезаурус инновационного педагогического процесса; приоритетному направлению «Методология и технология инновационной деятельности» - понятийнотерминологический тезаурус инновационной деятельности педагога; приоритетному направлению «Саморегуляция готовности к инновационной деятельности» - понятийнотерминологический тезаурус саморегуляции готовности к инновационной деятельности.

Логико-содержательное основание интеграции по приоритетному направлению «Опыт индивидуальной и групповой инновационной деятельности» определяют барьерные ряды инновационной деятельности и саморегуляции соответствующей готовности. Последние детализируют логико-смысловую компоновку содержания междисциплинарного модуля «Практикум инновационной деятельности и саморегуляции готовности к ней». Проектная характеристика в данном случае показывает посредством барьеров какого вида и каких барьерных последовательностей достигаются необходимые качественные сдвиги в структуре профессиональной готовности обучаемых.

Масштаб междисциплинарной интеерации. Данная характеристика применяется для оценки междисциплинарной интеграции главным образом в количественном отношении. Обобщенно говоря, это размер интеграции, указывающий, какую часть содержания профессионального образования она охватывает. Заметим, что интеграция может активно вовлекать во взаимодействие сведения и научную информацию, выходящие за рамки программ отдельных дисциплин. Для оценки масштаба интеграции целесообразно применять следующую градацию: мелкомасштабные, среднемасштабные и крупномасштабные [20];

Уровень междисциплинарной интеграции. Уровни интеграции отражают те изменения, которые происходят в составе и взаимосвязи учебных элементов. Для анализа и оценки образовательной программы возможно применение трех уровней междисциплинарной интеграции: низший уровень соответствует интеграции «по точкам»; средний - интеграции «по линиям»; высший - синтезу целостного новообразования [20].

\section{Технологизация подготовки к инновационной деятельности}

При разработке педагогического инструментария, наряду с субъектно-предметными, целе-функциональными и контент-ресурсными проектными характеристиками, необходимо достаточно полно учитывать специфику поэтапного становления готовности к инновационной деятельности (мотивацию, типы барьеров, препятствующие 
профессиональному росту, особенности принятия решений в ситуациях инновирования), а также особенности управления данным процессом.

Технологизация подготовки будущих педагогов к инновационной деятельности опирается на инструментально-технологические характеристики, которые включают: средства обучения, основные образовательные технологии, способы и приемы обучения, способы междисциплинарной интеграции, организационные формы.

Средства обучения. Проектная характеристика указывает на применяемые в образовательном процессе задания, задачи, упражнения, модели, схемы и т.п.

Основные образовательные технологии. Проектная характеристика показывает, с помощью каких технологий формируется готовность к инновационной деятельности.

Способы и приемы обучения. Данная характеристика показывает, какие способы и приемы применяются для управления учебно-познавательной деятельности студентов.

Способы междисциплинарной интеграции. Проектная характеристика указывает на совокупность дидактических действий, ориентированных на развитие той или иной формы междисциплинарной интеграции. Можно выделить следующие способы интеграции:

содержательный синтез представлений (объединение разрозненных представлений в некоторые обобщенные образы, например, о сфере образования в целом или конкретной педагогической системе);

содержательный понятийный синтез (например, синтез общепрофессиональных и специальных понятий с целью раскрытия содержания принципов и механизмов функционирования педагогической системы);

содержательный теоретический синтез (формирование целостного, концептуального взгляда на образование, инновационную деятельность в сфере образования);

содержательный синтез видов деятельности (формирование или модернизация структур деятельности на новой основе, например, в рамках задач осмысление актуальных проблем совершенствования образования, развитие саморегуляции в сложных ситуациях инновационной деятельности и др.).

Организационные формы. Проектная характеристика указывает на возможные варианты организации процесса подготовки к инновационной деятельности - лекции, семинары, тренинги, творческие обсуждения и т.п., виртуальные варианты индивидуальной и групповой работы в виде электронных телеконференций, форумов, синхронных и асинхронных во времени.

\section{Формирование организационно-управленческой поддержки}

Данный этап моделирования подготовки к инновационной деятельности связан с определением условий, необходимых для организации образовательного процесса, его информационного и методического обеспечения, включая условия по координации взаимодействия преподавателей вуза и педагогов базовых образовательных учреждения. К основным организационно-управленческим характеристикам следует отнести: кадровое обеспечение; координацию и кооперацию образовательного и организационного характера; учебно-методическое обеспечение; информационное обеспечение; материальнотехническое обеспечение.

Кадровое обеспечение. Проектная характеристика отражает состав и квалификацию преподавателей, непосредственно участвующих в подготовке будущих педагогов к инновационной деятельности. Практической реализации разработанной модели должна предшествовать специальная подготовка преподавателей вуза по актуальным вопросам педагогической инноватики, ключевым проблемам подготовки студентов к инновационной активности. Каждому преподавателю необходимо, как минимум, достаточно четко уяснить сущность и содержание проводимой подготовки, методы и приемы формирования у будущих педагогов инновационной активности, возможности преподаваемых дисциплин в решении поставленных задач.

Координация и кооперация образовательного и организационного характера. Речь идет о взаимодействиях преподавателей различных дисциплин, а также координации и кооперации преподавательского состава вуза и педагогов базовых образовательных учреждений в процессе подготовки студентов к инновационной деятельности. 
Учебно-методическое обеспечение. Проектная характеристика дает необходимые представления о применяемом учебно-методическом комплексе, включая междисциплинарную модульную программу, методические разработки, учебные пособия, пакеты дидактических материалов. В учебно-методическое обеспечение следует включить контрольно-аттестационный регламент, содержащий указания, как и $\mathrm{c}$ помощью чего оцениваются результаты подготовки к инновационной деятельности.

Информационное обеспечение. Информационное обеспечение предполагает создание условий для получения, хранения, накопления, передачи и обработки информации, необходимой для оперативного управления системой подготовки будущих педагогов к инновационной деятельности.

Материально-техническое обеспечение. Проектная характеристика указывает на наличие и применение в образовательном процессе мультимедийных средств, компьютерной техники, программных средств, информационных систем управления учебным процессом и др.

\section{Заключение}

Результаты моделирования системы подготовки к инновационной деятельности оформляются в виде междисциплинарной модульной программы, содержание которой рационально структурировать в двух частях. Первая часть программы включает набор междисциплинарных модулей, ориентированных на формирование информационную основу инновационной деятельности и саморегуляции готовности к ней. Вторая часть программы представляет собой междисциплинарный модуль, который оформляется в виде практикума по инновационной деятельности и саморегуляции готовности к ней.

Программа считается разработанной, если определены состав и содержание междисциплинарных модулей, бюджет учебного времени в целом и по каждому модулю; проведено распределение теоретических и практических занятий в системе взаимосвязи предметного обучения, педагогических практик и НИРС; установлена последовательность их проведения; подготовлены другие материалы учебно-методического комплекса.

\section{Примечания:}

1. Адольф В. А., Ильина Н.Ф. Инновационная деятельность педагога в процессе его профессионального становления: Монография. Красноярск: Поликом, 2007.

2. Ангеловски К. Учителя и инновации. М.: Просвещение, 1991. 159 с.

3. Лазарев В.С., Мартиросян Б.П. Педагогическая инноватика. М., 2006.

4. Мартиросян Б.П. Оценка инновационной деятельности школы. М.:Просвещение, 2003.

5. Морозов Е.П., Пидкасистый П.И. Подготовка учителей к инновационной деятельности // Советская педагогика. 1991. № 10. С. 88-93.

6. Сластенин, В.А., Подымова Л.С. Педагогика: инновационная деятельность. М.: изд. Магистр, 1997.

7. Ривкин Е.Ю. Профессиональная деятельность учителя в период перехода на ФГОС. Теория и технологии/ Е. Ю. Ривкин. Волгоград: Учитель, 2014.

8. Берков В.Ф. Значение компетентностного подхода в развитии образования на этапе перехода к информационному обществу // Инновационное образование : теория и практика: материалы Междунар. науч.-практ. конф., Минск, 22- 23 дек. 2011 г.; ГУО «Акад. последиплом. образования». Минск: АПО, 2011. С.23-28.

9. Бермус А.Г. Проблемы и перспективы реализации компетентностного подхода в образовании // Интернет-журнал "Эйдос". 2005. 10 сентября. http://www.eidos.ru/ journal/2005/ 0910-12.htm

10. Тюнников Ю.С. Проектные характеристики учебно-познавательных барьеров // Международный семинар по проблеме «Развитие творческих способностей личности в условиях гуманизации образования»: Тез. Выступлений. Сочи, 1996. С. 15-19.

11. Тюнников Ю.С. Проектирование содержания послевузовского дополнительного профессионального образования: концепция, проблемы, решения: Монография. Сочи: РИЦ СГУТиКД, 2010.

12. Вайндорф-Сысоева М.Е. Организация виртуальной образовательной среды в 
подготовке педагогических кадров к инновационной деятельности: автореф. дис. ... д. пед. наук. М., 2009.

13. Григорьева С.Г. Формирование инновационной культуры учителя начальных классов в процессе профессиональной подготовки. Автореф. дис. ... д. пед. наук. М., 2011.

14. Абасов 3. Подготовка учителей к работе в инновационной среде // Высшее образование в России. 2003. №10. С. 18-22.

15. Фокина В.Н. Формирование инновационной культуры преподавателя вуза: социологический аспект управления: Автореф. дис... канд. социол. наук. М., 2001. 21 с.

16. Айзенштадт А.Л. Инновационные проекты в преподавании социальногуманитарных дисциплин в вузе // Инновационное образование: теория и практика : материалы Междунар. науч.-практ. конф., Минск, 22-23 дек. 2011 г.; ГУО «Акад. последиплом. образования». Минск: АПО, 2011. С. 19-23.

17. Борисюк О.Л. Инновационная деятельность как ресурс качества образования студента университета// Инновационное образование : теория и практика : материалы Междунар. науч.-практ. конф., Минск, 22-23 дек. 2011 г.; ГУО «Акад. последиплом. образования». Минск: АПО, 2011. С. 28-32.

18. Титовец Т.Е. Междисциплинарная интеграция содержания профессионального образования как научная проблема // Интеграция образования. 2008. №4. C.86-88.

19. Бекренев А., Михелькевич В. Многоступенчатые структуры интегрированных систем образования // Высшее образование в России. 1996. № 3. С. 37-50.

20. Тюнников, Ю.С. Методика выявления и описания интегративных процессов в учебно-воспитательной работе СПТУ. М.: АПН СССР, 1988.

\section{References:}

1. Adol'f V. A., Il'ina N.F. Innovatsionnaya deyatel'nost' pedagoga v protsesse ego professional'nogo stanovleniya: Monografiya. Krasnoyarsk: Polikom, 2007.

2. Angelovski K. Uchitelya i innovatsii. M.: Prosveshchenie, 1991. 159 s.

3. Lazarev V.S., Martirosyan B.P. Pedagogicheskaya innovatika. M., 2006.

4. Martirosyan B.P. Otsenka innovatsionnoi deyatel'nosti shkoly. M.:Prosveshchenie, 2003.

5. Morozov E.P., Pidkasistyi P.I. Podgotovka uchitelei k innovatsionnoi deyatel'nosti // Sovetskaya pedagogika. 1991. № 10. S. 88-93.

6. Slastenin, V.A., Podymova L.S. Pedagogika: innovatsionnaya deyatel'nost'. M.: izd. Magistr, 1997.

7. Rivkin E.Yu. Professional'naya deyatel'nost' uchitelya v period perekhoda na FGOS. Teoriya i tekhnologii/ E. Yu. Rivkin. Volgograd: Uchitel', 2014.

8. Berkov V.F. Znachenie kompetentnostnogo podkhoda v razvitii obrazovaniya na etape perekhoda k informatsionnomu obshchestvu // Innovatsionnoe obrazovanie : teoriya i praktika: materialy Mezhdunar. nauch.-prakt. konf., Minsk, 22- 23 dek. 2011 g.; GUO «Akad. poslediplom. obrazovaniya». Minsk: APO, 2011. S.23-28.

9. Bermus A.G. Problemy i perspektivy realizatsii kompetentnostnogo podkhoda v obrazovanii // Internet-zhurnal "Eidos". 2005. 10 sentyabrya. http://www.eidos.ru/ journal/2005/ 0910-12.htm

10. Tyunnikov Yu.S. Proektnye kharakteristiki uchebno-poznavatel'nykh bar'erov // Mezhdunarodnyi seminar po probleme «Razvitie tvorcheskikh sposobnostei lichnosti v usloviyakh gumanizatsii obrazovaniya»: Tez. Vystuplenii. Sochi, 1996. S. 15-19.

11. Tyunnikov Yu.S. Proektirovanie soderzhaniya poslevuzovskogo dopolnitel'nogo professional'nogo obrazovaniya: kontseptsiya, problemy, resheniya: Monografiya. Sochi: RITs SGUTiKD, 2010.

12. Vaindorf-Sysoeva M.E. Organizatsiya virtual'noi obrazovatel'noi sredy v podgotovke pedagogicheskikh kadrov k innovatsionnoi deyatel'nosti: avtoref. dis. ... d. ped. nauk. M., 2009.

13. Grigor'eva S.G. Formirovanie innovatsionnoi kul'tury uchitelya nachal'nykh klassov v protsesse professional'noi podgotovki. Avtoref. dis. ...d. ped. nauk. M., 2011.

14. Abasov Z. Podgotovka uchitelei k rabote v innovatsionnoi srede// Vysshee obrazovanie v Rossii. 2003. №10. S. 18-22.

15. Fokina V.N. Formirovanie innovatsionnoi kul'tury prepodavatelya vuza: sotsiologicheskii aspekt upravleniya: Avtoref. dis...kand. sotsiol. nauk. M., 2001. 21 s. 
16. Aizenshtadt A.L. Innovatsionnye proekty $\mathrm{v}$ prepodavanii sotsial'no-gumanitarnykh distsiplin v vuze // Innovatsionnoe obrazovanie: teoriya i praktika : materialy Mezhdunar. nauch.prakt. konf., Minsk, 22- 23 dek. 2011 g.; GUO «Akad. poslediplom. obrazovaniya». Minsk: APO, 2011. S. 19-23.

17. Borisyuk O.L. Innovatsionnaya deyatel'nost' kak resurs kachestva obrazovaniya studenta universiteta// Innovatsionnoe obrazovanie : teoriya i praktika : materialy Mezhdunar. nauch.prakt. konf., Minsk, 22-23 dek. 2011 g.; GUO «Akad. poslediplom. obrazovaniya». Minsk: APO, 2011. S. 28-32.

18. Titovets T.E. Mezhdistsiplinarnaya integratsiya soderzhaniya professional'nogo obrazovaniya kak nauchnaya problema // Integratsiya obrazovaniya. 2008. №4. S.86-88.

19. Bekrenev A., Mikhel'kevich V. Mnogostupenchatye struktury integrirovannykh sistem obrazovaniya // Vysshee obrazovanie v Rossii. 1996. № 3. S. 37-50.

20. Tyunnikov, Yu.S. Metodika vyyavleniya i opisaniya integrativnykh protsessov v uchebnovospitatel'noi rabote SPTU. M.: APN SSSR, 1988.

\section{УДК 37}

\section{Моделирование подготовки будущих педагогов к инновационной деятельности с опорой на систему проектных характеристик}

\section{Юрий Станиславович Тюнников}

Сочинский государственный университет, Российская Федерация

354000, г. Сочи, ул. Советская, 26-а

Доктор педагогических наук, профессор

Аннотация. Моделирование системы подготовки будущих педагогов к инновационной деятельности производится в определенной проектной логике и процедурах, что возможно только посредством определенного набора проектных характеристик, учитывающих реальные возможности и особенности вуза. В статье ставится и решается проблема проектных характеристик, раскрывающих в своем наборе особенности построения, организации и функционирования системы подготовки к инновационной деятельности в конкретных условиях профессионального образования.

Ключевые слова: система подготовка будущих педагогов к инновационной деятельности, моделирование педагогической системы, проектные характеристики моделируемой системы. 